\title{
Neurological presentation of acute aortic syndrome: Type A intramural haematoma presenting as ischaemic hemisection of the spinal cord
}

\author{
Christopher Seet $\mathbb{C}^{1} \cdot$ James Walker ${ }^{1} \cdot$ Oliver Lyons $^{1} \cdot$ Rachel Bell $^{1}$
}

Received: 18 April 2020 / Accepted: 15 June 2020

(c) International Spinal Cord Society 2020

\begin{abstract}
Introduction Intramural haematoma (IMH) describes the presence of blood within the aortic wall, and is associated with a significant morbidity and mortality. Early diagnosis is essential for institution of medical, and sometimes surgical, management. Neurological complications have rarely been described during the initial presentation of IMH, or other forms of acute aortic syndrome.

Case presentation We describe a 56-year-old man who presented with sudden onset chest pain and left leg weakness and numbness, and the loss of right leg pain and temperature sensation. CT Angiography showed a Type A intramural haematoma extending from the ascending to the infra-renal aorta. He was managed successfully with cerebrospinal fluid drainage and thoracic endografting to cover the intimal entry lesion. His neurological symptoms improved and he remained well at 3 years with minor residual neurological deficits.

Discussion Spinal cord infarction is a rare but documented complication of acute aortic syndrome; Brown-Séquard syndrome typically results from a traumatic injury. To the best of our knowledge, this is the first report of IMH presenting with Brown-Séquard syndrome. This case highlights the need to consider acute aortic syndromes in a patient presenting with chest pain and acute neurological symptoms.
\end{abstract}

\section{Introduction}

Acute aortic syndrome (AAS) comprises penetrating aortic ulcer (PAU), intramural haematoma (IMH) and aortic dissection (AD) [1]. All of these conditions may progress to aortic rupture and early diagnosis and prompt medical management are essential. IMH accounts for $6-10 \%$ of all AAS in the West, and up to $30 \%$ of cases in Asia. The aetiology is unclear but IMH is often associated with a small communication with the aortic lumen [2-4]. Radiologically, IMH is defined on computed tomography (CT) as the presence of regional aortic wall thickness $>7 \mathrm{~mm}$ in the absence of a dissecting membrane, intimal disruption, or false lumen flow [5]. Like AD, IMH may be classified as Type A-affecting the ascending aorta (with or without

Rachel Bell

rachel.bell@gstt.nhs.uk

1 Vascular Surgery, Guy's and St Thomas' NHS Foundation Trust, London, UK more distal involvement) or Type B-affecting only the descending aorta [1]. Along with an initial aortic diameter $>50 \mathrm{~mm}$, involvement of the ascending aorta is an important predictor of increased mortality [3]. Over time up to $47 \%$ of $\mathrm{IMH}$ evolve into $\mathrm{AD}$, but they may remain static or spontaneously regress $[2,3]$.

AAS classically presents with acute chest or thoracic back pain [1]. They can also be associated with central or peripheral nervous system involvement. Neurological symptoms can include Horner's syndrome, stroke, seizures and coma. Spinal cord ischaemia occurs in between 2 and $9 \%$ acute $\mathrm{AD}[6,7]$. Spinal cord ischaemia in IMH is extremely rare, with only a few case reports published [810]. We report an acute presentation of Brown-Séquard syndrome (BSS) caused by Type A IMH.

\section{Case report}

A 56-year-old man presented to the emergency department with a short history of sudden onset interscapular back pain, rapidly followed by progressive left leg weakness and 
numbness. He was a smoker, but had no known history of hypertension and took no regular medications. He also reported a history of two previous operations in his lower spine for a herniated disk 4 and 6 years prior to admission. Other than a blood pressure of $186 / 93 \mathrm{mmHg}$, cardiovascular, respiratory and abdominal physical examinations were unremarkable, and all peripheral pulses were palpable. Examination of the cranial nerves and upper limbs was unremarkable. In the right lower limb, power and light touch sensation was normal, reflexes were brisk with a flexor plantar response, but he had reduced sensation (International Standards for Neurological Classification for Spinal Cord Injury (ISNCSCI) grade 1) to pin prick and temperature below the level of T12 [11]. He had ISNCSCI grade 0 weakness in entire the left lower limb, with grade 1 sensation of light touch below the level of T12 (with sacral sparing), but normal grade 2 sensation of pin prick and temperature, with brisk reflexes and an extensor plantar response. Voluntary anal contraction and sensation to deep anal pressure were not tested. He was diagnosed with an American Spinal Injury Association Impairment Scale incomplete grade D injury at the level of T12. An initial electrocardiogram was normal. He had a raised C-reactive protein $(40 \mathrm{mg} / \mathrm{L}$, reference range $0-5 \mathrm{mg} / \mathrm{L})$ and D-dimer $(4.29 \mathrm{mg} / \mathrm{L}$, reference range $0-0.5 \mathrm{mg} / \mathrm{L})$, and a normal Troponin I $(0.01 \mathrm{ng} / \mathrm{mL}$, reference range $0-0.04 \mathrm{ng} / \mathrm{mL})$. CT angiography demonstrated a circumferential Type A IMH extending from the ascending to the infra-renal aorta. There was a small region demonstrating localised 'stranding' of contrast into the media of the descending aorta (Fig. 1a, b). A diagnosis of AAS (IMH) was made and he was initially managed with an intravenous infusion of labetalol, targeting a systolic blood pressure $\leq 120 \mathrm{mmHg}$. Transthoracic echocardiography confirmed the ascending aortic haematoma but the aortic root was not dilated and no regurgitation or pericardial effusion was seen.

Magnetic resonance imaging of his spine was not performed as this could delay further treatment, and a cerebrospinal fluid (CSF) drainage catheter was inserted at the L3/4 level. This was followed immediately by improvement in power in the left lower limb. Hip flexion, hip extension, knee flexion and knee extension improved to ISNCSCI grade 3 power. He had grade 2 power in plantar flexion and dorsiflexion. Sensation in the limb had improved, although remained reduced throughout the leg. Drainage was continued to allow a maximum CSF pressure of $12 \mathrm{cmH}_{2} \mathrm{O}(8.83 \mathrm{mmHg})$, limited to a maximum drainage rate of $30 \mathrm{ml} / \mathrm{h}$.

Ongoing chest pain over the next $24 \mathrm{~h}$ prompted repeat $\mathrm{CT}$ angiography demonstrating development of a PAU-like crater in the mid-descending aorta, with new bilateral pleural effusions (Fig. 1c, d). Under local anaesthesia a stentgraft (TAG $37 \times 15 \mathrm{~mm}$, Gore, Arizona, USA) was placed via a right femoral arteriotomy to cover the PAU. Post-deployment balloon moulding was not done, the left subclavian origin was not excluded and there was no endoleak. His neurological symptoms continued to improve and in the left limb he had ISNCSCI grade 4 power in the hip and knee flexors, and grade 3 in the knee extensors, plantar flexors, long toe extensors, and grade 2 in the dorsiflexors. He was able to mobilise with a frame on post-operative day 4 . Light touch sensation remained reduced throughout the left lower leg, although sensation was improved proximally. He was discharged home pain-free on the ninth post-operative day. On discharge, he was referred to outpatient rehabilitation with the neurophysiotherapy team. Repeat CT aortography a year later demonstrated complete resolution of the intimal IMH without aneurysm formation (Fig. 1e). After 3 years, he remains well but requires a crutch to walk long distances.

\section{Discussion}

Brown-Séquard first published a description of the syndrome resulting from lateral hemi-lesion to the spinal cord in 1849 [12]. Damage to the decussated ascending spinothalamic tract results in the loss of contralateral pain and temperature sensation a few levels below the lesion, whilst section of the corticospinal tract (which decussates in the medulla) results in an initial ipsilateral flaccid (and then later spastic) paralysis. The loss of the dorsal columns produces ipsilateral loss of proprioception and vibration and light touch sensation. BSS usually follows traumatic injury with an apparent mechanism [13]. Alternative potential causes of BSS include AAS, disc herniation or a synovial cyst, spontaneous epidural haematoma, iatrogenic ischaemia (e.g., after unintentional embolisation), infection (e.g., cysticercosis), transverse myelitis and decompression sickness [7, 14-17].

The most common neurological presentation in $\mathrm{AD}$ is acute ischaemic stroke, often due to the involvement of the common carotid artery origin. Malperfusion of a limb will produce an ischaemic neuropathy, but can be differentiated from a spinal cause of neuropathy by the absence of palpable pulses. Peripheral nerves can also be injured via direct compression by an expanding false arterial lumen. Spinal cord infarction is rare, occurring in $\sim 2 \%$ of cases of $\mathrm{AD}$ and is typically due to disruption of the vascular network supplying the spinal cord $[7,18]$. Ischaemic spinal cord injury has been described in a few cases of IMH, with some variability in symptom severity, but to the best of our knowledge BSS has never been described [8-10, 19-22]. In this case, the findings on clinical examination correlate with the radiological findings, with the T12 sensory level corresponding to the thoracic segment of the IMH, and is near the region that was worst affected, and the evolving aortic ulcer. 
Fig. 1 CT angiography at presentation, 48 hours, and 1 year. CT angiogram at presentation demonstrating localised contrast 'stranding' in the aorta (arrowhead in a) and IMH in the ascending (black arrows in b) and descending (white arrows in b) aorta. Repeat CT angiogram after $48 \mathrm{~h}$ showing progression of the initial stranding into a PAU-like crater (arrows) in the descending aorta in axial (c) and sagittal (d) planes. CTA 1 year post surgery showing resolution of IMH (e) around the endograft.
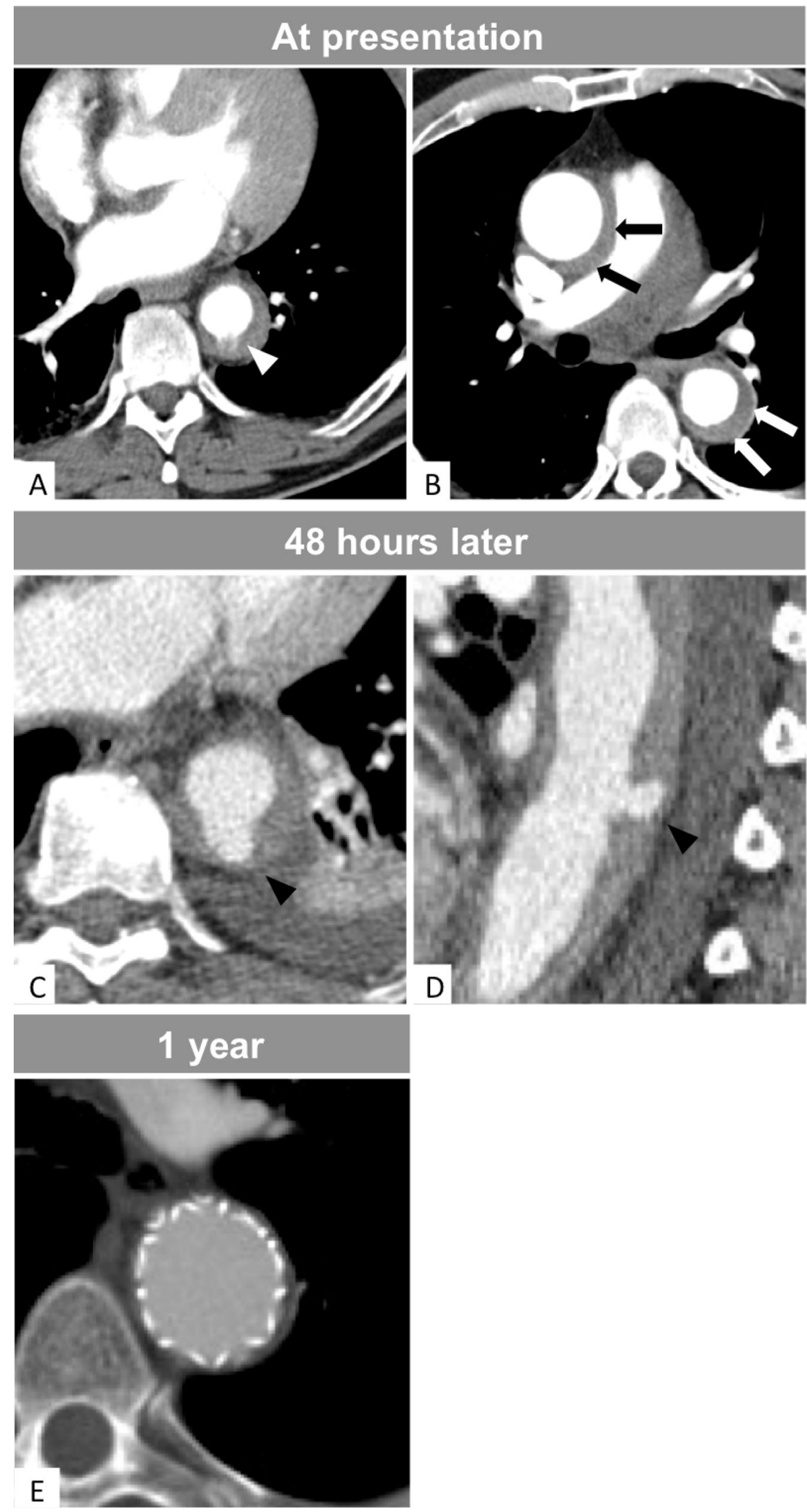

However, the exact reason for a unilateral spinal cord injury despite a circumferential IMH is unknown. Spinal cord ischaemia is associated with increased complication rates in
$\mathrm{AD}$, as well as increased long-term mortality. Resolution of cord injury improves both early and long-term mortality [6]. There is currently no international consensus on therapeutic 
strategies for ischaemic cord injury. CSF drainage can help to improve spinal cord perfusion and prevent cord injury after aortic surgery. It may also have a role in AAS, although this is currently unclear, with conflicting results reported $[6,23,24]$. Type A IMH is usually managed by urgent open surgery via a median sternotomy, utilising cardiopulmonary bypass to allow replacement of at least the ascending aorta, with an associated mortality of $8-14 \%$ [25]. There have been very few reports of endovascular management of IMH, and almost all are for Type B, rather than Type A [26-29]. The aim of deploying a thoracic stentgraft is to cover the primary lesion and prevent IMH progression to dissection or rupture. An unusual therapeutic strategy is possible (as in this case) when Type A IMH appears to be related to an intimal lesion in the descending aorta, and so is amenable to endovascular treatment $[26,29,30]$. The serial CT angiography in this case demonstrates the sometimes rapidly evolving nature of the culprit entry lesion.

Spinal cord perfusion pressure is determined by the difference between mean arterial pressure (MAP) and CSF pressure. Ischaemic spinal cord injury from other causes (e.g., after elective thoracoabdominal aneurysm endografting) would typically be treated with hypertension to increase the MAP and improve cord perfusion, typically requiring vasopressors, but this is not without risk in the setting of AAS, when a low blood pressure is therapeutic. An alternative approach would be early thoracic endografting followed by therapeutic hypertension (albeit the safety of therapeutic hypertension after endografting is unknown). Here, we pursued hypotension as treatment for the IMH, and CSF drainage to treat the spinal cord injury and improve cord perfusion.

In addition to the management of the acute presentation, follow-up and management of atherosclerotic disease risk factors is important. Potential complications include dissection, aneurysm formation and rupture of the aorta and its branches, and follow-up imaging is recommended. Medical therapy including blood pressure and heart rate control, as well as statins where indicated, are key. Other risk reduction measures such as smoking cessation and lifestyle modification also need to be implemented [1].

Our case highlights that AAS has a pleiomorphic presentation and should be considered as a cause of acute neurological presentations, and CT angiography is diagnostic.

\section{Compliance with ethical standards}

Conflict of interest The authors declare that they have no conflict of interest.

Publisher's note Springer Nature remains neutral with regard to jurisdictional claims in published maps and institutional affiliations.

\section{References}

1. Bossone E, LaBounty TM, Eagle KA. Acute aortic syndromes: diagnosis and management, an update. Eur Heart J. 2018;39:739-49.

2. Evangelista A, Mukherjee D, Mehta RH, O'Gara PT, Fattori R, Cooper JV, et al. Acute intramural hematoma of the aorta: a mystery in evolution. Circulation.2005;111:1063-70.

3. Vilacosta I, Aragoncillo P, Canadas V, San Roman JA, Ferreiros J, Rodriguez E. Acute aortic syndrome: a new look at an old conundrum. Heart. 2009;95:1130-9.

4. Pelzel JM, Braverman AC, Hirsch AT, Harris KM. International heterogeneity in diagnostic frequency and clinical outcomes of ascending aortic intramural hematoma. J Am Soc Echocardiogr. 2007;20:1260-8.

5. Hoey ET, Wai D, Ganeshan A, Watkin RW. Aortic intramural haematoma: pathogenesis, clinical features and imaging evaluation. Postgrad Med J. 2012;88:661-7.

6. Sandhu HK, Charlton-Ouw KM, Jeffress K, Leake S, Perlick A, Miller CC 3rd, et al. Risk of mortality after resolution of spinal malperfusion in acute dissection. Ann Thorac Surg. 2018; 106:473-81.

7. Gaul C, Dietrich W, Erbguth FJ. Neurological symptoms in aortic dissection: a challenge for neurologists. Cerebrovasc Dis. 2008; 26:1-8.

8. Tsushima T, Al-Kindi S, Patel T, Kalra A. Atypical complications of aortic intramural hematoma: Paraplegia resulting from spinal cord infarction. Int J Cardiol Heart Vasc. 2019;22:154-5.

9. Ferguson JD, Moore N, Banning AP. Intramural aortic haematoma causing ischaemia of the spinal cord. Heart 1996;75:533.

10. Motoyoshi N, Komatsu T, Moizumi Y, Tabayashi K. Atypical paraplegia after aortic intramural hematoma. J Thorac Cardiovasc Surg. 2003;125:409-10.

11. American Spinal Injury Association. International standards for neurological classification of spinal cord injury. Richmond, VA: American Spinal Injury Association; 2019.

12. Brown-Séquard C-É. De la transmission croisée des impressions sensitives par la moelle épinière. Comptes rendus Société biologie. 1851;1850:12.

13. Ropper AH, Samuels MA, Klein J. Adams and Victor's principles of neurology. 10th ed. New York: McGraw-Hill Education Medical; 2014.

14. Kunam VK, Velayudhan V, Chaudhry ZA, Bobinski M, Smoker WRK, Reede DL. Incomplete cord syndromes: clinical and imaging review. Radiographics.2018;38:1201-22.

15. Kim SW, Ju CI, Kim HS, Kim YS. Brown-sequard syndrome caused by a cervical synovial cyst. J Korean Neurosurg Soc. 2014; 55:215-7.

16. Moon SJ, Lee JK, Kim TW, Kim SH. Idiopathic transverse myelitis presenting as the Brown-Sequard syndrome. Spinal Cord. 2009; 47:176-8.

17. Tseng WS, Huang NC, Huang WS, Lee HC. Brown-Sequard syndrome: a rare manifestation of decompression sickness. Occup Med. 2015;65:758-60.

18. Etz CD, Kari FA, Mueller CS, Silovitz D, Brenner RM, Lin HM, et al. The collateral network concept: a reassessment of the anatomy of spinal cord perfusion. J Thorac Cardiovasc Surg. 2011;141:1020-8.

19. Ullery BW, Hobbs RD, Cheung AT. Reversible spinal cord ischemia as a complication of acute aortic intramural hematoma. Vascular.2015;23:427-31.

20. Yu PJ, Cassiere HA, Liang D. Acute intramural hematoma of the aorta complicated by spinal cord ischemia. J Card Surg. 2013;28:742-4. 
21. Zhu HG, Zha BS, Liu B. Aortic intramural hematoma presenting as paraplegia progressed into segmental aortic dissection. Thorac Cardiovasc Surg. 2012;60:548-51.

22. Blanco Jimenez J, Vargas Nunez JA, Yebra Bango M, Cristobal Varela C, Durantez Martinez A. Brown-Sequard syndrome secondary to dissecting aortic aneurysm. Rev Clin Esp. 1997;197:299-301.

23. Sandridge L, Kern JA. Acute descending aortic dissections: management of visceral, spinal cord, and extremity malperfusion. Semin Thorac Cardiovasc Surg. 2005;17:256-61.

24. Khan NR, Smalley Z, Nesvick CL, Lee SL, Michael LM 2nd. The use of lumbar drains in preventing spinal cord injury following thoracoabdominal aortic aneurysm repair: an updated systematic review and meta-analysis. J Neurosurg Spine. 2016;25:383-93.

25. von Kodolitsch Y, Csosz SK, Koschyk DH, Schalwat I, Loose R, Karck M, et al. Intramural hematoma of the aorta: predictors of progression to dissection and rupture. Circulation. 2003; 107:1158-63.
26. Monnin-Bares V, Thony F, Rodiere M, Bach V, Hacini R, Blin D, et al. Endovascular stent-graft management of aortic intramural hematomas. J Vasc Interv Radiol. 2009;20:713-21.

27. Schoder M, Grabenwoger M, Holzenbein T, Domanovits $H$, Fleischmann D, Wolf F, et al. Endovascular stent-graft repair of complicated penetrating atherosclerotic ulcers of the descending thoracic aorta. J Vasc Surg. 2002;36:720-6.

28. Kaya U, Colak A, Becit N, Ceviz M, Kocak H. Endovascular stent graft repair of localized acute aortic intramural hematoma: a case report and literature review. Eurasian J Med. 2017;49:211-3.

29. White C, Lapietra A, Santana O, Burke W 3rd, Beasley R, Conde $\mathrm{C}$, et al. Endovascular treatment of an acute ascending aortic intramural hematoma. Int J Surg Case Rep. 2014;5:126-8.

30. Eggebrecht H, Plicht B, Kahlert P, Erbel R. Intramural hematoma and penetrating ulcers: indications to endovascular treatment. Eur J Vasc Endovasc Surg. 2009;38:659-65. 